\title{
Small and Medium Entrepreneurship in Saudi Arabia's Vision 2030 and Its Role in Reducing Unemployment in the Kingdom of Saudi Arabia
}

\author{
Esmat Mohamed Abdel Moniem el sayed ${ }^{1}$ \\ ${ }^{1}$ College of Business, University of Jeddah, Kingdom of Saudi Arabia \\ Correspondence: Esmat Mohamed Abdel Moniem el sayed, College of Business, University of Jeddah, Kingdom of \\ Saudi Arabia. E-mail: emalsayed@uj.edu.sa
}

Received: January 1, 2020

Accepted: February 18, 2020

Online Published: March 29, 2020

doi:10.5430/rwe.v11n1p229

URL: https://doi.org/10.5430/rwe.v11n1p229

\begin{abstract}
SMEs (small and medium-sized enterprises) account for 60 to 70 percent of jobs in most OECD (Organization for Economic Cooperation and Development) countries with a particularly large share in Italy and Japan, and a relatively smaller share in the United States. Throughout; they also account for a disproportionately large share of new jobs, especially in those countries which have displayed a strong employment record.

In Saudi Arabia, more than two-thirds of the population are younger than 30 and about 100,000 graduates enter the job market each year. The present paper discusses what measures should be taken and highlights the importance of understanding the relationship and interaction between unemployment and entrepreneurship. The present research focuses on studies that explain small and medium-sized entrepreneurship and its role in reducing unemployment in the Kingdom of Saudi Arabia. Both qualitative and quantitative approaches are used to collect data that may contribute to a better understanding of the employment issues of Saudi young men and women. Besides; we introduce entrepreneurship Survey Questionnaire; this survey has focused mainly on understanding the relationship and interaction between unemployment and entrepreneurship. In this survey, a more balanced view is taken by examining the factors which contribute to creating more job opportunities.
\end{abstract}

Keywords: small and medium-sized enterprises, entrepreneurship, Saudi Arabia, unemployment, job opportunities

\section{Introduction}

Small and medium-sized enterprises (SMEs) are the backbone of Europe's economy. They represent 99\% of all businesses in the European Union (EU). In the past five years, they have created around 85\% of new jobs and provided two-thirds of the total private sector employment in the EU. The European Commission considers SMEs and entrepreneurship as key to ensuring economic growth, innovation, job creation, and social integration in the EU.

Small and medium enterprises (SMEs) are the backbone of any economy. Nowadays when governments or international institutions put forward a plan or policy, they show great concern about the role of SMEs in the economy as they know that these businesses are crucial to economic growth and development. Yet despite the importance of such enterprises for King of Saudi Arabia (KSA), obstacles often stand in the way of their development, such as financial and political issues, lack of technology adoption and unskilled workers. Furthermore, SME owners of these businesses tend to have informal financing borrowing from relatives, friends and rotating credit associations instead of formal financing, which requires long and complicated procedures (including registering as an entity).

Many researchers consider most owner-managers of these enterprises to be entrepreneurs because they start the venture, administer the business, and are responsible for its failure or success. Both SMEs and entrepreneurs share the broader ecosystem. Indeed, "most new firms are small firms so that a substantial part of the entrepreneurship literature is concerned with the dynamics of small and medium enterprises (SMEs)" (Naudé, W., 2008).

Despite these many similarities, the literature holds that there are a few differences between SMEs and entrepreneurs - most being related to credit provision. As such, policy remedies to barriers facing SMEs in the Middle East and North Africa have primarily involved the establishment of special funds and agencies to fill gaps left by the financial and banking system. Most reparative work on work on MSMEs and entrepreneurship in Egypt has focused on barriers to growth from technical and economic angles, with little attention thus far having been paid to nonfinancial obstacles such as political and institutional challenges. Our report will shed light on these challenges. 
According to GCF 2015 (global competitiveness forum -Competitive Governments 2015) SMEs in KSA, context and opportunities, small and medium enterprises (SMEs) including microenterprises play an important role as a cornerstone in fostering growth, employment and income generation in most economies. In KSA, the role of SMEs is pivotal to supporting many national priorities e.g.,

- Creating a more resilient and diverse economy with a more dynamic private sector participation.

- Enabling innovation and helping transition to a knowledge-based economy, through home-grown champions that can compete internationally.

- Achieving a more balanced and inclusive growth, by addressing the bottom of the income pyramid, which includes micro-enterprises.

SMEs in KSA is at the heart of the economy as they account for $99 \%$ of establishments and $62 \%$ of total employment which is in line with global averages of $60-75 \%$. The ICT sector has become vibrant for SMEs especially after the deregulation and the e-commerce market becoming one the most advanced in the region. Although SMEs are mostly dominating the technology sector, they have also had major contributions to the agricultural output, especially in the eastern provinces. Having SMEs contribute to the development of specie sectors is important in moving them to become key players within the value chain of bigger corporations. SMEs in KSA have untapped potential that can be unlocked by addressing several challenges that they face, primarily around access to talent, information, government requirements, and finance. A survey carried out by the Council of Saudi Chamber of Commerce and Industry (CSCCI) and the United Nations Industrial Development Organization documents that the main challenge facing SME owners in KSA is the lack of credit, finance, and capital. Less than $2 \%$ of KSA banks' total lending goes to SMEs compared to $14 \%$ in non-GCC countries. Without the right incentives for lenders to increase the ownership of credit to SMEs or the proper policy tools to manage their risks, banks cannot be expected to give SMEs a larger share of their lending portfolios. Government initiatives have devoted significant resources to extend development programs to SMEs in recent years. There are currently 50+ government and non-profit entities that directly or indirectly engage in SME promotion activities that span a large spectrum of services (e.g., financing, capability building, networking and mentoring) and offer investors relevant investment opportunities.

According to trading economics, the unemployment rate in Saudi Arabia decreased to 5.60 percent in the fourth quarter of 2016 from 5.70 percent in the third quarter of 2016. Unemployment rate in Saudi Arabia averaged 5.53 percent from 1999 until 2016, reaching an all-time high of 6.30 percent in the fourth quarter of 2006 and a record low of 4.35 percent in the fourth quarter of 1999. In Saudi Arabia, the unemployment rate measures the number of people actively looking for a job as a percentage of the labor force. This page provides Saudi Arabia unemployment rate actual values, historical data, forecast, chart, statistics, economic calendar, and news. Saudi Arabia unemployment rate actual data, historical chart and calendar of releases - were last updated on May of 2017.

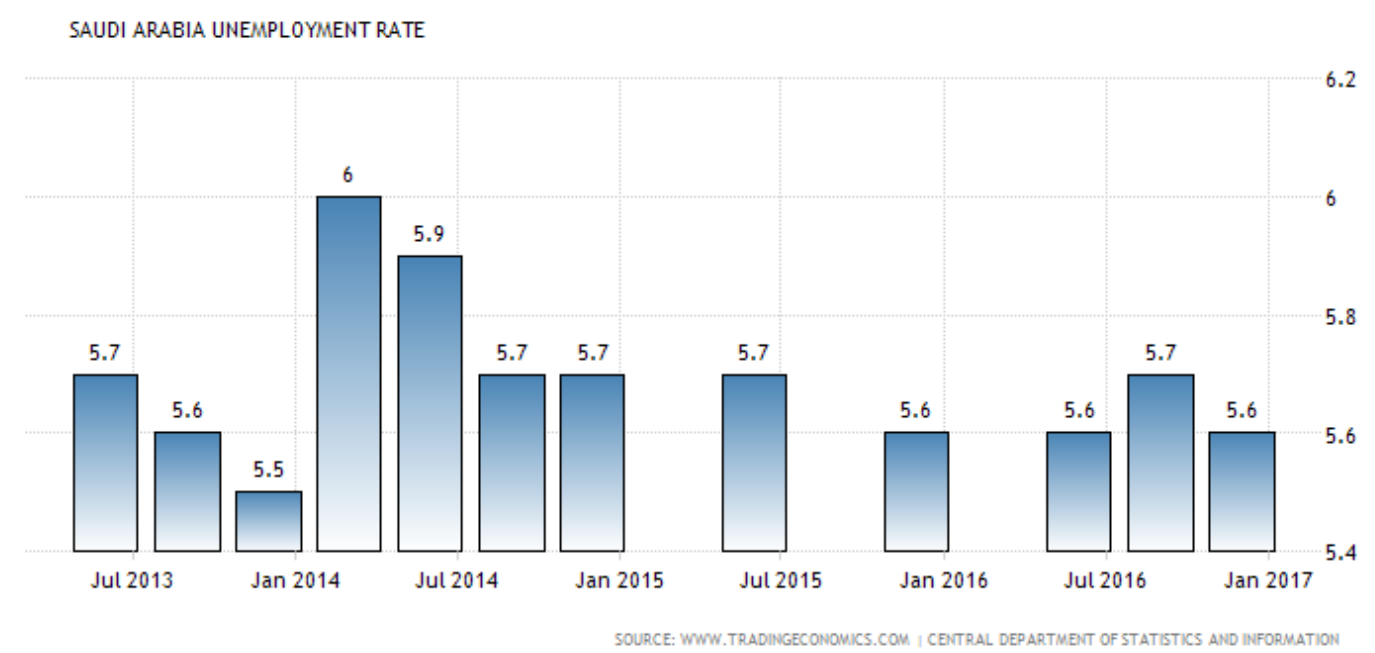




\begin{tabular}{llllll}
\hline Saudi Arabia Labour & Last & Previous & Highest & Lowest & Unit \\
\hline$\underline{\text { Unemployment Rate }}$ & 5.60 & 5.70 & 6.30 & 4.35 & Percent \\
\hline$\underline{\text { Unemployed Persons }}$ & 751811.00 & 699164.00 & 751811.00 & 437648.00 & \\
\hline$\underline{\text { Population }}$ & 31.74 & 31.52 & 31.74 & 4.04 & Million \\
\hline$\underline{\text { Labor Force Participation Rate }}$ & 56.50 & 55.30 & 56.50 & 47.80 & Percent \\
\hline$\underline{\text { Employed Persons }}$ & 11067.67 & 11067.70 & 11067.70 & 6167.00 & Thousand \\
\hline$\underline{\text { Retirement Age Men }}$ & 62.00 & 62.00 & 62.00 & 60.00 & \\
\hline$\underline{\text { Retirement Age Women }}$ & 55.00 & 55.00 & 55.00 & 55.00 & \\
\hline
\end{tabular}

\section{Literature Review}

Entrepreneurship and small and medium-sized enterprises (SMEs) are inextricably linked. The role of entrepreneurship is pivotal in creating economic growth and employment within the SME sector. "Entrepreneurs' innovativeness and personality play a key role in the adoption of innovations in SMEs" (Marcati, A. et al., 2008). SMEs within the UK and Europe account for $99 \%$ of all European businesses. They provide two-thirds of private-sector jobs and significantly contribute to economic growth. Globally, whilst no precise data exist, World Bank research estimates that roughly $95 \%$ of businesses across the world are SMEs. To further emphasize the significance of SMEs, in the US, the share of US firms with less than 500 employees (less than 500 being the US criteria for an SME) is 99.9 percent.

An essential aspect to SME development is rooted within a vibrant entrepreneurial sector. "Entrepreneurs are people who sense opportunities, innovate and take risks in the face of uncertainty and develop new goods and services". LyudmilBorisov of LGB Direct, an outsourced sales, and marketing firm, is quoted saying "fostering entrepreneurs is absolutely crucial to creating a stable and strong economy"

However, when considering the role that entrepreneurship plays in support of SMEs, it is pertinent to reflect upon the confusion in using the terms entrepreneurship and SME interchangeably (Darren, L., \& Conrad, L., 2009). As previously remarked, entrepreneurship and SMEs are inextricably linked, though that is not to suggest they are the same concept. Herein the problem lies, whilst there is no doubt over the value of entrepreneurship and SMEs within an economy, the stimulation of each can be more protracted with singular policies targeting both collectively. Prior to exploring the dichotomy, it is necessary to consider how both entrepreneurship and SMEs are defined.

One of the key issues encountered with entrepreneurship, and arguably a factor that contributes to its amalgamation with SMEs, is the lack of a commonly accepted definition. The organization for economic co-operation and development (OECD) considers entrepreneurship as the combination of three facets working in unison "conductive framework conditions, well-designed government programs and supportive cultural attitudes". In its more simplistic form, it might be expressed as an individual who starts or progresses a business; however, its contribution is multi-layered, it goes beyond merely the formation of a business. Joseph Schumpeter, a renowned economist, describes the role of entrepreneurship as central to capitalist development through its provision of innovative products, methods of production, new markets and new organizational forms (Schumpeter, J.A., 1934). Such a process transcends merely economic growth in its most literal sense, to provide for innovative technology, opportunities to the younger generation, creation of jobs and generating a positive impact on society. Darren, L., \& Conrad, L., 2009 refer to entrepreneurship as a process by which an individual identifies, undergoes evaluation and subsequently exploits the opportunity(s) identified. Likewise, Ogundele, 2007 similarly uses the term process in recognition of opportunities within their environment by which to take advantage of.

Hill and McGowan, 1999 opined that entrepreneurship is seen as a process whereby an individual identifies an opportunity which through the organizing of resources are able to exploit such opportunities. It is therefore evident that 
eminent researchers refer to entrepreneurship as comprising a process, the element of risk-taking, a corresponding reward and expending time and effort.

Small and medium-sized enterprises (SMEs) are, as the name suggests, companies or businesses that are small and medium in size. Due to variances globally on the criteria of SMEs, a number of definitions exist. Darren L. et al., (2009) states that the measures for defining SMEs should relate to the number of employees and size. Baumback defines SME with respect to the level of employment, size of asset value and dollar sales. The European Commission defines SME on the basis of the number of employees and either turnover or balance sheet total, it provides a further breakdown classifying SMEs as medium-sized, small and micro differentiated according to the criteria above. However, Gibson and Van der Vart, (2008) discredit these approaches for it is too closely modeled on the manufacturing sector. For example, they criticize the adoption of the number of employees, as in many developing nations, due to stringent employee taxes it is commonplace to circumvent this through hiring "students" or "consultants" therefore under-representing their true number of employees.

It is contended that whilst entrepreneurship and SMEs are distinct, they both strive for the same objective. They are both attributed to the creation of jobs, economic growth, economic development, and economic transformation. Similarly, they also share the same factors which can lead to success or failure. Such factors are considered to be the cultural setting, location, environment, and individual characteristics that can impede or propel both entrepreneurship and SMEs. The significance of these factors should not be underestimated as they can, either in combination or individually, seal the fate of either venture.

Research has also considered whether the individual traits possess by entrepreneurs and SME owners share similarities. Lucky and Olusegun (2005) concluded that both respectively share initiative, perseverance, diligence, commitment to the agreement, patience, systematic planning, creative problem solving, self-confidence, ability to influence others, commitment. In one respect this should not come as much of a surprise as SMEs are typically the brainchild of an entrepreneur.

However, whilst they may share the same beginnings, it is the SME owner that will advance to develop and utilize a set of skills not akin to an entrepreneur. SME owners will invariably take on the managerial skills in order for them to manage their firms successfully. People management, for example, is not a skill required for an entrepreneur who is only responsible for their own time. Further, an SME owner will take on a wealth of other duties not applicable to an entrepreneur such as formally registering their company, an obligation to pay taxes, providing skills-based training to employees and charitable donations or contributions to local community projects.

As revealed in considering some of the available definitions of the two terms, entrepreneurship can be considered a process whereby SMEs are firms in the literal sense and we can surmise that the process of entrepreneurship is one that if successful leads to the creation of SMEs. Contributing to the blurred lines of entrepreneurship and SMEs are concepts such as 'creative entrepreneurship' which is proposed can assist SMEs in fast-moving environments such as digital media to foster growth within their business against the challenge of doing so (Lucky, E.O. \& Olusegun, A.I., 2012).

If we consider that the building block of an SME is the creation of an idea aimed to exploit a business opportunity then we are drawing upon the definition of entrepreneurship. Therefore following that logic we might suggest that the role that entrepreneurship plays in supporting SMEs is in providing the grassroots for the creation of SMEs, in the same way, an initial aptitude for learning an instrument is a prerequisite to playing in a band.

An example that clearly illustrates the role of entrepreneurship supporting SMEs is with tourism SMEs. Where entrepreneurs envisage that an area will be attractive to visitors it creates an opportunity for new enterprise creation. Further, where interdependence is recognized it can be harnessed to create a substantially more attractive destination on the basis of a number of small enterprises co-ordinating to provide a successful destination. To illustrate, this was witnessed in Hay-on-Wye with its wealth of bookshops which have thrived on entrepreneur-led development (Johns, N, and Mattsson, J, 2005). and similarly in North Conway where three business partners bought an abandoned railway station and opened the Conway Scenic Railroad, almost 30 years later it has transformed the small village into a significant tourist attraction supporting a plethora of associated businesses (Murphy, L. et al., 2011). In these examples, the local tourism was generated by entrepreneurs creating SMEs that were subsequently bolstered by the interaction between the public and private sector.

Recognizing the deeply entrenched link between entrepreneurship and SMEs reflects the driver behind policies aimed at promoting entrepreneurship such as the Entrepreneurship 2020 Action Plan which is the European Commission's proposal for maximizing entrepreneurship potential at a European, national, regional and local level. The three key 
aims of which are entrepreneurship educations, improving the business environment so entrepreneurs can grow and flourish, and role models and outreach to specific groups (Murphy, L. et al., 2011).

However, it should be noted that whilst the significant focus is expended on policies that attract entrepreneurship it is by no means a certainty for economic development. For example, a study in Finland suggested that the average size of new start-ups after three years was still only a single entrepreneur. Further that the majority of new firms will only ever employ its founder. This largely explains why countries with the highest levels of entrepreneurs are developing countries such as Uganda and Peru; it is less out of government policies to generate economic growth than out of necessity. In that respect, entrepreneurship serves a much greater role in supporting SMEs.

However, far more promising statistics are those that state that in the UK, $4 \%$ of newly formed enterprises had provided $50 \%$ of jobs created by all new firms 10 years later. Similarly, in the US, 3\% of the fastest-growing companies were responsible for over 70\% of new jobs by new companies from 1992-96. Davidson P. (1995) however contends that job creation is chiefly derived through a much larger percentage of smaller firms.

The issue with the lack of a universally agreed definition has been summarised by Gibson and Van der Vart in highlighting that inconsistencies of definitions adopted can result in three key distortions: firstly in the distribution of donor funds for developments within the private sector; secondly that turnover is proffered as a more suitable means of expressing a business's size than the more commonly adopted number of employees or value of assets; lastly that utilizing a single definition for SMEs across countries in varying states of economic development can lead to further distortions.

Unemployment in the Kingdom is still in the double digits at 11.6 percent; one of the world's highest for a national unemployment rate. As for unemployment among women, it has reached 32.8 percent in the Kingdom. The figure is the highest in the world, according to the International Monetary Fund (IMF).

In its recent report, the General Authority for Statistics showed that the number of Saudis over 15 years of age has reached 13.8 million. Of these, 8.2 million are outside the labor market and only 5.6 million are considered inside the Kingdom's labor market. The unemployment rate is obtained by dividing the 646,000 employed Saudis by 5.6 million, giving the unemployment rate of 11.6 percent.

These employed statistics include the estimated 500,000 positions, which artificially reduce the national unemployment rate significantly. Due to the absence of transparency in the Authority's statistics, it's difficult to get an accurate picture of employment in the Kingdom.

Evidently, any international consensus on what should constitute an SME is some way off, which could also be levied at the understanding of what constitutes entrepreneurship. Both terms attract inconsistent qualification through disparate comprehension of their definition yet are keenly debated with the apparent perception that the audience adopts the same definition as the author.

Entrepreneurship occupies a pivotal position within a market economy; entrepreneurs ignite an economy and in turn, stimulate economic growth. Entrepreneurship serves as the bedrock for SMEs, which in turn is the kernel for development into much larger companies. Therefore, in considering the role that entrepreneurship serves in supporting SMEs is akin to the analogy of a seed into a seedling, if supported and the necessary resources, opportunities, etc. are available it will support the creation of SMEs. This underlies the thinking behind the promotion of entrepreneurship through governmental policy changes, to reap the rewards of vibrant SMEs and its corresponding benefits to the economy, governments are seeking to promote entrepreneurship through addressing the issues that can serve as a barrier. However, a more precise strategy would steer academics, policymakers, and media away from conjoining the two terms as whilst there is demonstrable overlap they remain two distinct terms. Whilst we might consider that the creation of jobs, economic growth, economic development, and economic transformation are objectives for both entrepreneurship and SMEs they remain at disparate points within the holistic process of taking an idea and growing it into a business. Therefore, it flows that in stimulating both concepts within an economy requires diverging strategies, a partitioning of policy to truly stimulate entrepreneurial behaviors such as addressing the availability of funds and resources, addressing market entry restrictions, training, and education. Then separately targeting the growth of SMEs through measures including increased governmental support, assistance with business rates, lending and late payment cash flow allowances.

\section{Unemployment in the Kingdom of Saudi Arabia}

In Saudi Arabia, the unemployment rate measures the number of people actively looking for a job as a percentage of the labor force, Therefore, extensive research has investigated, and the literature showed an important role of entrepreneurship in job creation and unemployment reduction. 
For a few years, GCC governments have attempted to facilitate national workers' entry into the domestic labor market and substitute for expatriates, with mixed results. An oil-driven development model has provided rapid economic growth and diversification into a variety of sectors; however, citizens of the GCC continue to face significant underemployment. Population growth rates in all six GCC states are at $3 \%$ or more, with large numbers of expatriates in some states, such as the UAE and Qatar, outnumbering locals creating a disproportionately young population across the GCC. This projected demographic growth will add new national entrants into the labor market for years to come. Increasing private sector engagement in creating job opportunities for nationals is crucial (Stephen Farrell \& Michael Mamish., 2013).

In Saudi Arabia, the largest of the GCC countries by population and Gross national product (GNP), 400,000Saudis, on average, reach working age every year. The Kingdom needs to create three million job opportunities by 2015 , and six million jobs by 2030, to handle the surge of youths looking for employment. The public sector is already over-staffed and, given its inability to stimulate real on-oil output directly, it will be the private sector that plays a pivotal role in creating more jobs for nationals. Unaddressed, unemployment could reach $40 \%$ for youths aged between 20 and 24 , and higher for women. Creating appropriate job opportunities for nationals, and reducing current unemployment, is a critical focus of GCC governments. Another key aim of the region's labor nationalization includes reducing dependence on expatriate workers and capturing and reinvesting capital that would otherwise flow overseas in the form of remittances and increased self-enabled economic competitiveness.

Among the oil-rich GCC countries, Saudi Arabia has the largest native population and a high citizen to expatriate ratio. A fast-growing population and falling oil prices can be a volatile combination if there are a significant number of unemployed people in the population pool. This potential source of worry is what the country has been seeking to address. The late King Abdullah launched the Hafiz program which provides a monthly subsidy of SR 2,000 to support and encourage serious job seekers. Some 2.6 million people, 14 percent male and 86 percent female, have benefited from the program. In order to qualify for the allowance, jobseekers must show that they are seriously looking for a job. The basic objective of this financial allowance is to help job seekers get permanent and stable employment and not rely on government subsidies as a source of income. The program was one of a group of incentives and schemes ordered by the late King to support those searching for employment. A massive higher education assistance boost through the King Abdullah Foreign Scholarship Program in Saudi Arabia which runs until 2020 has benefited more than 160,000 students who were funded by this program to pursue higher studies in reputable universities worldwide.

To support local employment, the government has deported hundreds of thousands of undocumented foreign workers. The country's labor ministry has tightened rules for employing foreign labor in companies insisting that these businesses look to the domestic market first. With the assistance of the Ministry of Education, job fairs have been organized in the Kingdom with major domestic and international companies offering employment opportunities to Saudi graduates. Applicants with higher credentials are quickly picked up by major petrochemical firms, but many others complain of being offered jobs far below their expectations. Many reasons are given as to why young Saudis remain unemployed or are unemployable. While there is a range of job openings in the country, many young Saudi jobseekers lack the required qualifications and skills specified by employers. HR professionals blame an education system that has failed to realize the needs of the job market. Historically, the private sector has not been able to match the salaries and benefits which first-time job hunters hope to receive if employed by the government. Private sector jobs are seen to offer low salaries, shaky job security, and unattractive packages while requiring a commitment of long working hours. Saudi workers in private companies also accuse their employers of not taking into consideration the social and economic pressures that employees bring with them to their work environment. A recent study conducted by the Human Resources Development Fund indicated that 45 percent of young Saudis refuse to work for private companies because of the attitude of employers.

\section{Entrepreneurship as a Solution to Youth Unemployment in the Kingdom of Saudi Arabia}

SMEs account for $99.7 \%$ of all Saudi enterprises 1 but make a modest contribution of only $20 \%$ to the country's GDP [Figure 2]. Employees working in the SME sector represent $51 \%$ of the total employment in the country.

Early this year, Saudi Arabia's Vision 2030 was announced as a transformation blueprint for achieving the Kingdom's ambitious long-term goals. The vision is based on three main themes: (1) a vibrant society; (2) a thriving economy; and (3) an ambitious nation. The second theme states the need to leverage opportunities for creating economic value and systems for entrepreneurs and SMEs. The vision aims to develop the required tools to "unlock [Saudi Arabia's] promising economic sectors, diversify [its] economy and create job opportunities." The vision also underscores SMEs as "important agents of economic growth that create jobs, support innovation, and boost exports." However, the vision documents also state that the SME sector in Saudi Arabia is not an as strong contributor to GDP as in developed 
economies. It highlights that SMEs in Saudi Arabia face the challenge of complex policy and regulations, lack of access to funding, and finding the necessary skills.

As such, according to the vision, Saudi Arabia will strive to support SMEs and entrepreneurship by developing business-friendly regulations, driving access to funding, building international partnerships, and giving SMEs a greater share of government bids. The vision also emphasizes larger roles for SMEs. To help realize this vital sector's full potential, the SME Authority was recently established and is expected to review laws and regulations, remove obstacles, facilitate access to funding, and enable entrepreneurs to market and export their products.
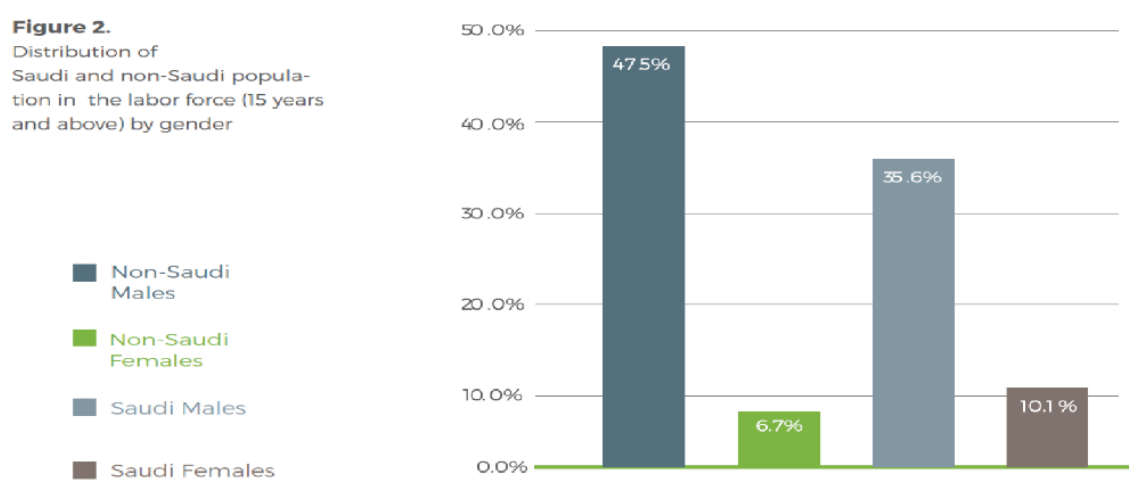

\section{Problem of the Saudi Market}

The government cannot be in the business of absorbing all Saudi job seekers, so it has turned to the private sector for help. Some business leaders have responded to the call. Dr. Abdulrahman Hayjan, a member of the Saudi Shoura (legislative) Council, said that unemployment should be treated in an innovative way "as the Kingdom is not an impoverished country that is facing budget problems". He said: "Our labor market needs to be regulated in a way that ends this problem permanently. The number of expatriate workers in our market makes one wonder whether we have a real unemployment problem like other countries or the problem lies in the fact that we have plenty of jobs but our youth think they aren't appropriate for them in terms of the nature of work and salary."

An economist believes that the problem of the Saudi market is twofold. "First, most Saudis rely on the government sector to create jobs for them while the private sector does not play any role in that. The problem is obvious and the results could be catastrophic in the future if the private sector does not start offering more opportunities for Saudis," he explained.

\section{Programs Are Undertaken by GCC Governments to Solve Youth Unemployment}

GCC governments have been pushing on multiple fronts to address the problem. Those efforts range from long-term strategic policies to short-term desired outcomes. One example of long-term strategic outcomes from GCC governments was to increase spending on education, vocational training, workforce engagement, employment information dissemination, and job search support, to better equip the national workforce with private-sector job requirements. Enforcing quotas for nationals in the workforce, specifying certain jobs for nationals only, and tightening work visa permits are some short-term solutions engaged. Other mid-term measures include fees for hiring expatriate labor. Short- and mid-term measures, if not implemented carefully, may lead to labor market distortion, forcing private sector companies to hire nationals instead of cheaper, more productive expatriates, which may reduce their competitiveness and force them to consider relocation and outsourcing (Stephen Farrell \& Michael Mamish., 2013).

This combination of incentives to increase national employment and regulate the labor market for the private sector has created mixed feelings with employers, where some believe the governments' policies are inconsiderate to their competitiveness and ability to profitably grow while dealing with those measures. Many of these employers have lobbied successfully with the political elite and gained stay measures in several sectors for long periods of time.

A key rationale used in this lobbying is the gradual replacement of expatriates with nationals as a prudent economic strategy, particularly because of the region's demographics, but it will not be successful if it focuses on job substitution at the expense of job creation. Neither will it be successful if it results in making private sector companies less competitive, and deters foreign direct investment. 
The Kingdom of Saudi Arabia (KSA) is one GCC country that implemented several market-based strategies across the spectrum (Stephen Farrell \& Michael Mamish., 2013), such as:

Nitakat: a program assessing the nationalization performance of enterprises (i.e., the percentage of Saudis in the enterprise in comparison with the total number of employees within the organization). The better the organization's classification, the easier it is for it to act in the labor market.

Hafez: the first GCC unemployment program, where unemployed Saudi nationals are provided a monthly benefit while looking for employment.

Takat: an employment match-making process using several virtual and non-virtual media to facilitate job seeker meetings with private sector employers.

Reserving specific job categories for Saudis such as security, HR and administration. Unemployment among women received special attention, and all retail sales positions for feminine products are now restricted to Saudi females.

\section{Programs Have Taken by the Saudi Government to Solve Youth Unemployment}

1. To increase women's employment, the Saudi government has tried to create more job opportunities. Employers have been urged to establish gender-segregated work areas and plans have been announced to lift a ban on female lawyers arguing cases in courtrooms. In an interview with the Washington Post in November 2012, the Saudi Labour Minister Adel Fakeih said his department was trying to create jobs that allow women to work from home.

2. In addition, the Saudi government has taken steps to increase the number of Saudi nationals working in the private sector. In June 2011, the Saudi Ministry of Labour introduced a new system called 'Nitaqat'. Through the Nitaqat-system, the Saudi government hopes to gradually replace expatriate workers with Saudi workers. Under the new policy, companies are incentivized to increase their percentage of Saudi employees; businesses with a low percentage of Saudi employees are penalized by having work visas for their non-Saudi workers denied.

3. The Saudi government has also introduced the Hafiz-program, which provides Saudi jobseekers a monthly allowance for a maximum period of one year, conditional upon their participation in job searches and training activities.

4. Despite these measures, there are still signs of distress within Saudi society. One of the most active conversations currently taking place on Twitter, loosely translated as "Salaries are not enough" is almost entirely fuelled by Saudi users.

5. The discussion has gone viral with hundreds of tweets per second and millions of tweets per week on the topic. With the hashtag \#salary_is_not_enough, Twitter users are urging the Saudi government to act against poor job prospects, low wages, and the rapidly rising cost of living.

6. While the Nitaqat-system aims to increase the number of Saudis working in the private sector, it does not actually change its structure which is primarily based on low-cost foreign labor and the Kingdom's comparative advantage in energy-intensive industries. Dr. Steffen Hertog, an expert on political economy in Saudi Arabia based at the London School of Economics, noted in a recent article for the Carnegie Endowment for International Peace that less than 400,000 of the 4 million expatriate-held jobs in the private sector commanded a salary of more than 3,000 Saudi Riyals (\$800) a month in 2011.

7. This means there are only a few positions in the private sector for which Saudis would even consider applying. The private sector in the Kingdom is mainly dominated by big business conglomerates which are the main beneficiaries of government contracts because of their close ties to the regime. Starting entrepreneurs, therefore, find it difficult to develop their businesses with 'government red tape' fuelling patronage, ultimately resulting in a stagnant private sector that lacks innovation and a sense of entrepreneurship. This is a big obstacle to the development of a more diversified economy that would increase the number of suitable, high-paying jobs available to the Saudi youth.

8. The measures taken by the Saudi government regarding employment have also stopped short of fully addressing women's employment. Lifting these restrictions has the potential, however, of triggering a confrontation between the regime and the conservative religious establishment.

9. Tensions between the Saudi government and the religious establishment recently came to the fore when King Abdullah sacked his hard-line adviser Sheikh Abdelmohsen al-Obeikan after the sheik criticized the king's decision to relax gender segregation.

10. The status of the Kingdom of Saudi Arabia in the field of entrepreneurship In Latin America and the 
Caribbean, only a fifth of Puerto Ricans see entrepreneurship as a good career choice (the lowest in the GEM sample), compared to $95 \%$ of Guatemalans (the highest in the GEM sample).In Europe, positive perceptions range from $40 \%$ among the Finns and Swiss to $78 \%$ for the Netherlands. In Asia and Oceania, less than half the working-age adults in India, the Republic of Korea and Malaysia see entrepreneurship as a good career compared to $81 \%$ in Saudi Arabia and Turkey.

11. Opportunity perceptions at either extreme of the GEM sample as a whole can be seen in economies in Europe as well as in Asia \& Oceania. Greece (13\%) and Russia (18\%) show the lowest levels for this indicator, while Sweden $(79 \%)$ and Saudi Arabia (82\%) are at the top end of the GEM sample. Belize also reports opportunity perception levels of over70\%; conversely, in Bulgaria and Slovakia, less than a quarter of adults perceive entrepreneurial opportunities in their area. Thereof the economies in Asia and Oceania United Arab Emirates, Saudi Arabia and Kazakhstan - have established business rates of around 2\%; in the same region, Thailand (27\%) and Lebanon (20\%) are ranked 2nd and 3rd respectively for this indicator. Thailand is a particularly interesting case - not only does this economy report the second-highest established business rate in the GEM sample, but the established business rate is considerably higher than the TEA rate (27\% compared to $17 \%$ ). Latin America and the Caribbean the range is from 12\% in Colombia to 88\% in Jamaica, while in Asia and Oceania rates range from 23\% in Qatar to 86\% in Saudi Arabia (see part 3, Table 6 for results on job creation by economy and region).

12. Three economies in Asia and Oceania exhibit the highest rates of entrepreneurs expecting to generate six or more jobs Qatar (52\%), Turkey (48\%) and Taiwan (40\%); interestingly, three of the economies with the lowest scores for this indicator are in the same region, with Indonesia, India and Saudi Arabia all reporting rates of $5 \%$ or less.

\section{SAUDI ARABIA}
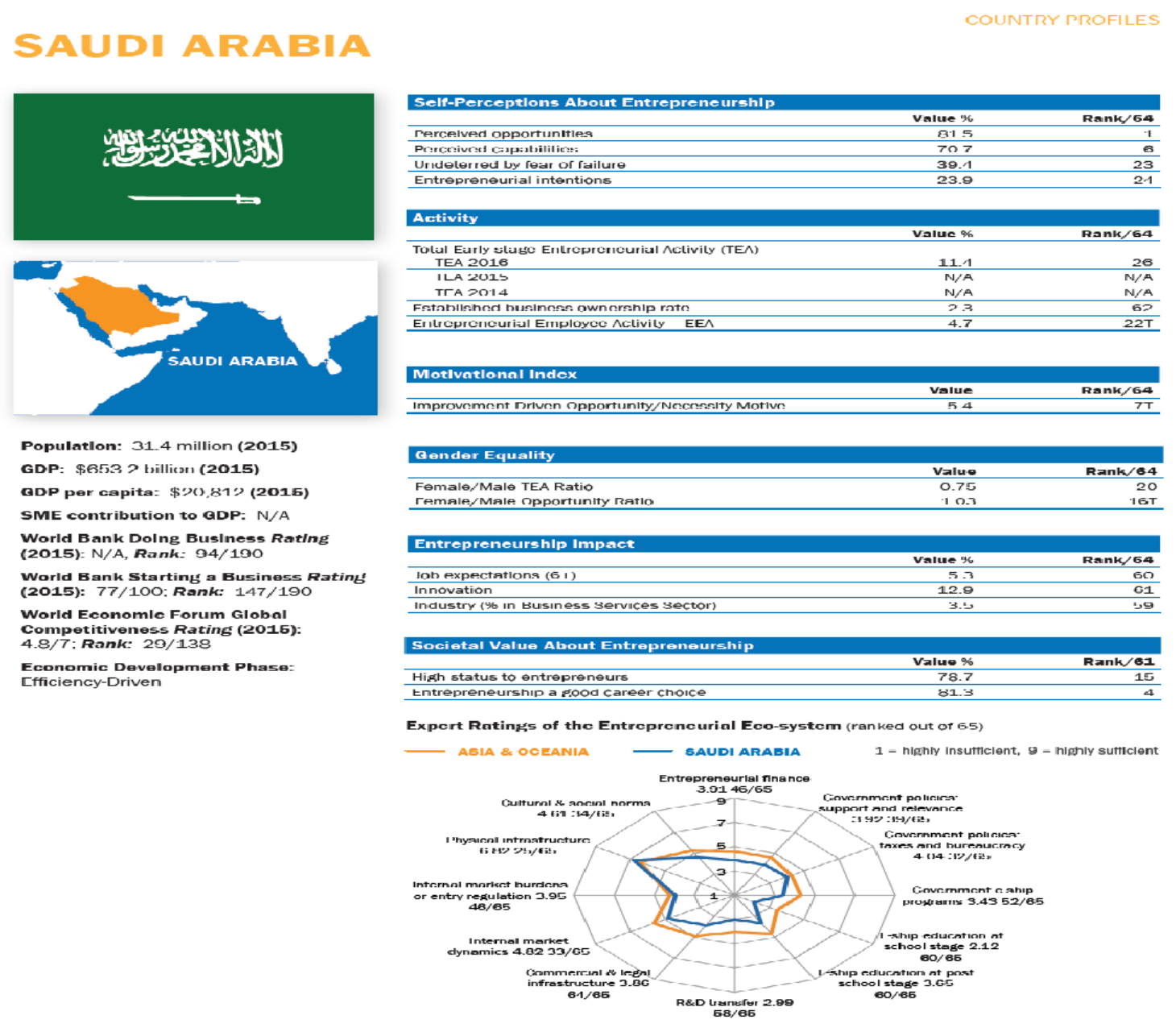

Populatlon: 31.4 million (2015) GDP: \$653 $>$ billicm (2015) GDP per capita: $\$$ ग0,81' (2015) SME contribution to GDP: N/A World Bank Dolng Business Rating World Bank Starting a Business Rating (2015): $77 / 100$. Rank: 147/190 World Economle Forum Global 4.8/7: Rank: 29/138 Economic Development Phase: Efficiency-Driven 
13. Saudi Arabia, as a country with a high youth unemployment rate, recently adopted policies designed to encourage entrepreneurship and SMEs. The massive injection of public funds and the efforts of policymakers to encourage entrepreneurship could not move Saudi youth from unemployment to entrepreneurship unless the country overcomes several obstacles and deals with challenges facing the coming generation.

\section{Analysis of Entrepreneurship Survey}

Both qualitative and quantitative approaches are used to collect data which may contribute to a better understanding of the employment issue of Saudi young men and women. Besides; we introduce entrepreneurship Survey Questionnaire; this survey has focused mainly on understanding the relationship and interaction between unemployment and entrepreneurship. In this survey, a more balanced view is taken by examining the factors which contribute to create more job opportunities and to identify the extent to which youth accept to work in Small and medium enterprises (SMEs) and what incentives and motives that enable them to do so, in addition to identifying the obstacles that prevent them from achieving this, and to identify the interest of women in the Kingdom in entrepreneurship and small companies and identify the role of media if it is influential in the field of entrepreneurship.

This questionnaire includes 20 questions that sampled various community groups. The number of participating samples reached one hundred and eleven (111) samples, in which women constituted $15 \%$.

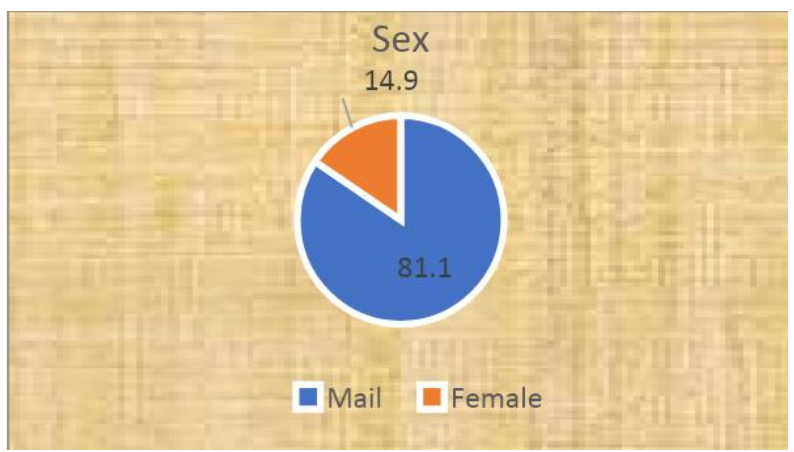

The age of the participants in the questionnaire was represented as follows: Ages less than 20 years constituted 15\%, Ages 20 to 30 years constituted $20.7 \%$, ages $30-40$ years constituted $46 \%$, ages $40-50$ years constituted $18 \%$ and age over 50 years constituted $15 \%$. Such representation is a great advantage due to the inclusion of all age groups of the society under study.

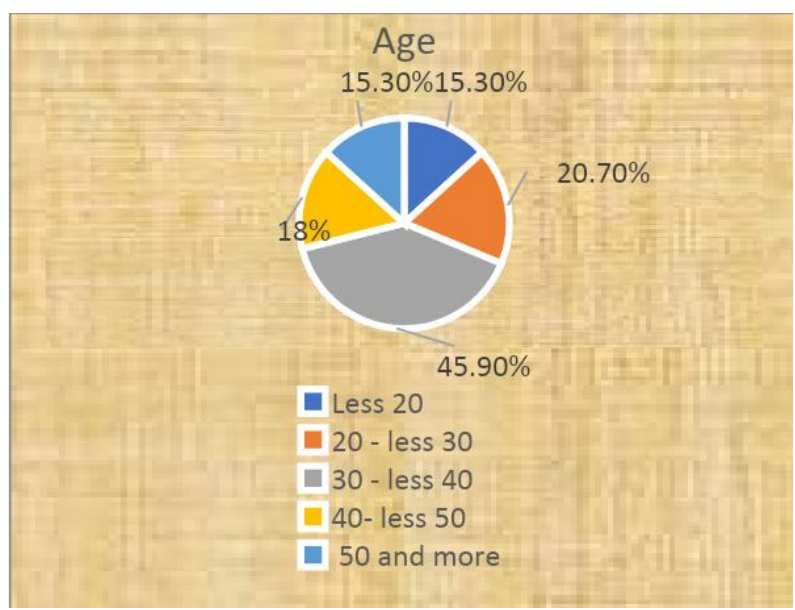

As for the scientific qualifications of the participants; Holders of a degree less than Bachelor's degree were 9\%, Bachelor's degree holders were 18\%, Master's degree holders were 35\% and Ph.D. holders were $38 \%$. 


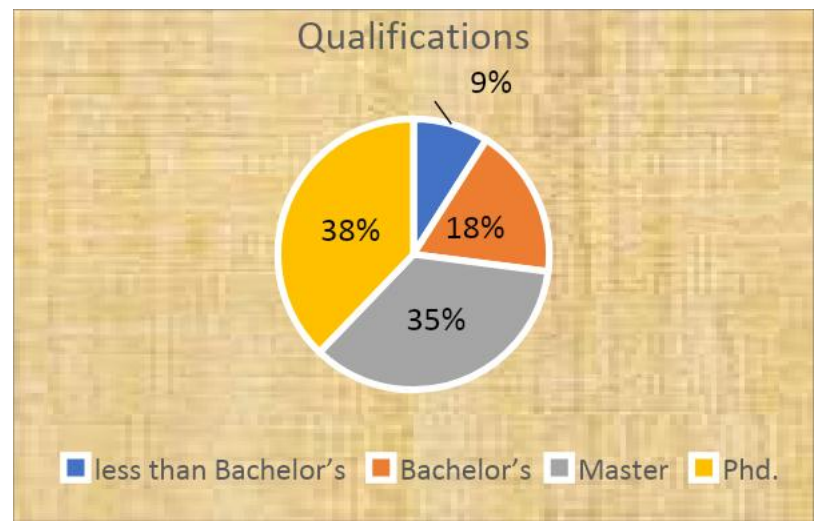

As for the sampled sectors of jobs, the government sector was represented by $67 \%$, the private sector was sampled by $15 \%$ and others were sampled by $18 \%$.

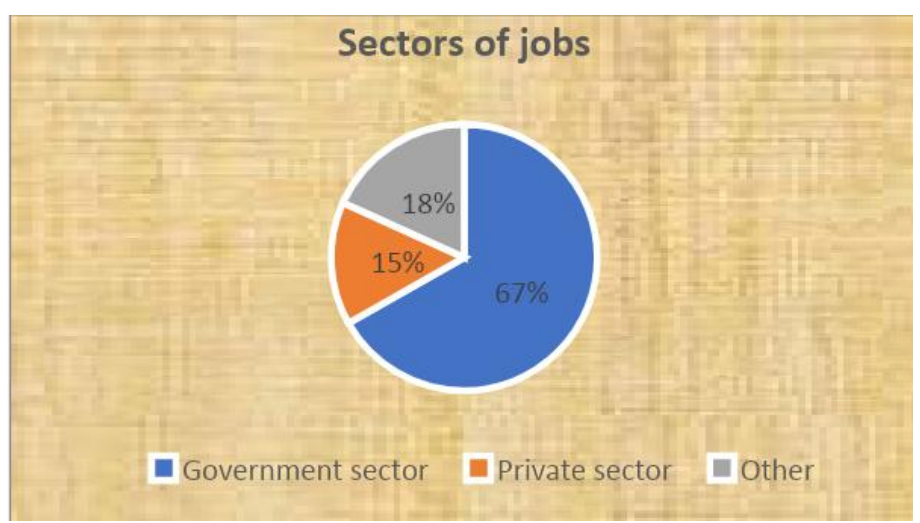

As for work experience, those whose work experience ranged from 5 years to 15 years were sampled with almost equal percentages, whereas those whose work experience exceeded 15 years reached $35 \%$.

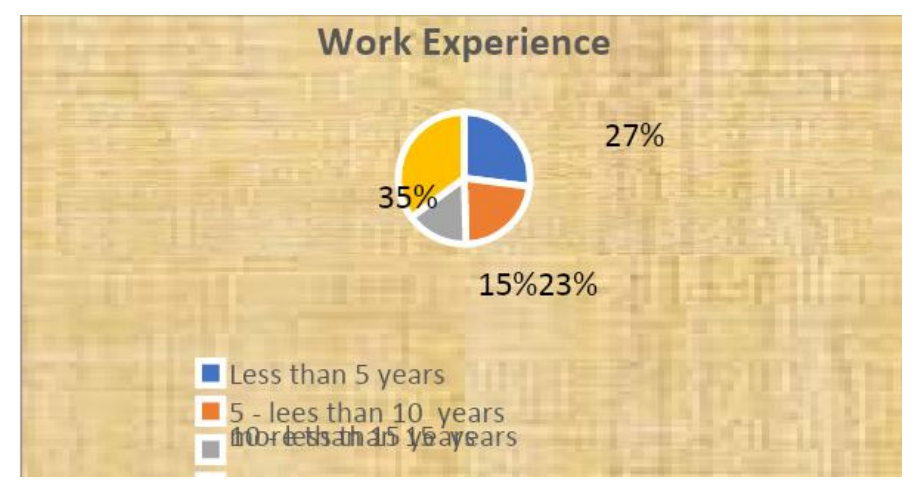

Besides that; those with more than 9-year experience in using data technology constituted $62 \%$ and those with other durations in work experience were almost equal in percentages. However, the questionnaire included all different categories of users of information technology. 


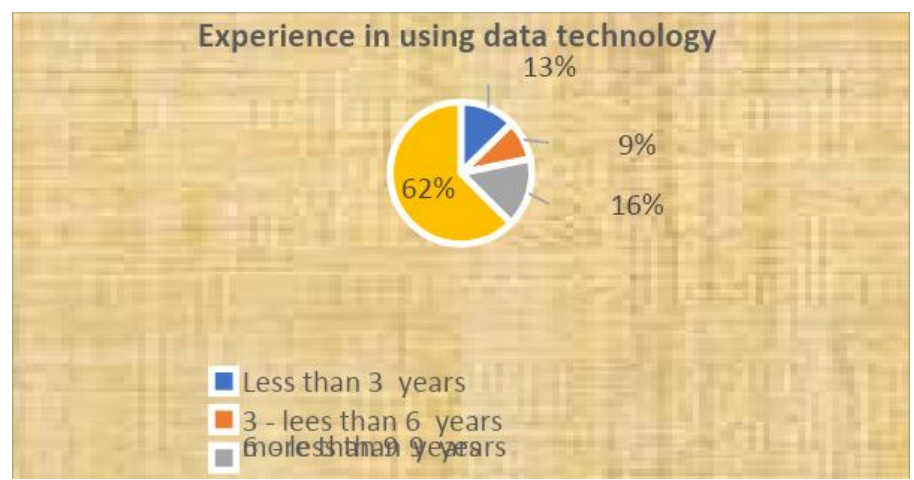

As for the question: "Are you considering setting up a project for you in the next five years?" The answers were "yes" by $81 \%$. This is a good indicator of working in small businesses and entrepreneurial projects in the Kingdom.

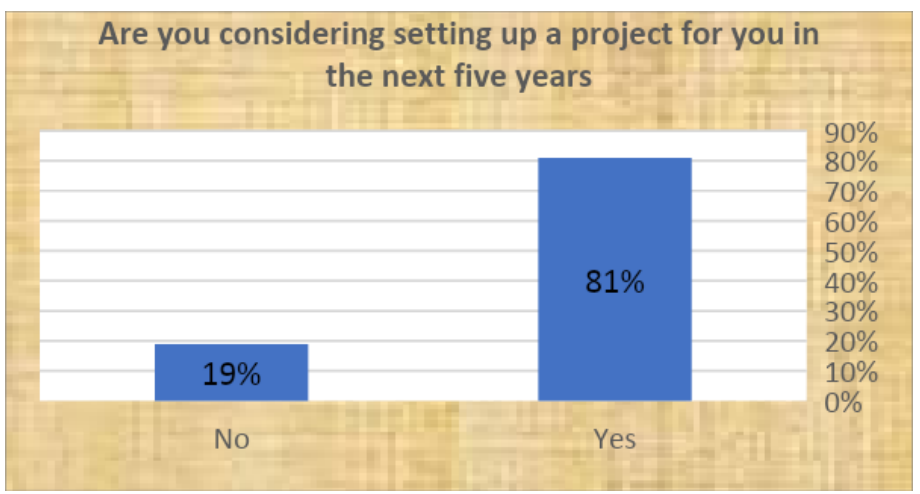

As for the question: "Are you willing to give up your current job in order to set up a business of your own?" we found that $67 \%$ of participants refused to leave the job. This means that the concept of adhering to government work is firmly rooted in young people, even though they are thinking of setting up a project of their own for the next five years. This indicates that it is essential to increase the level of training and confidence in microenterprise projects and entrepreneurship as well as increase the awareness of their benefits so as to find an alternative to keeping young people in government positions.

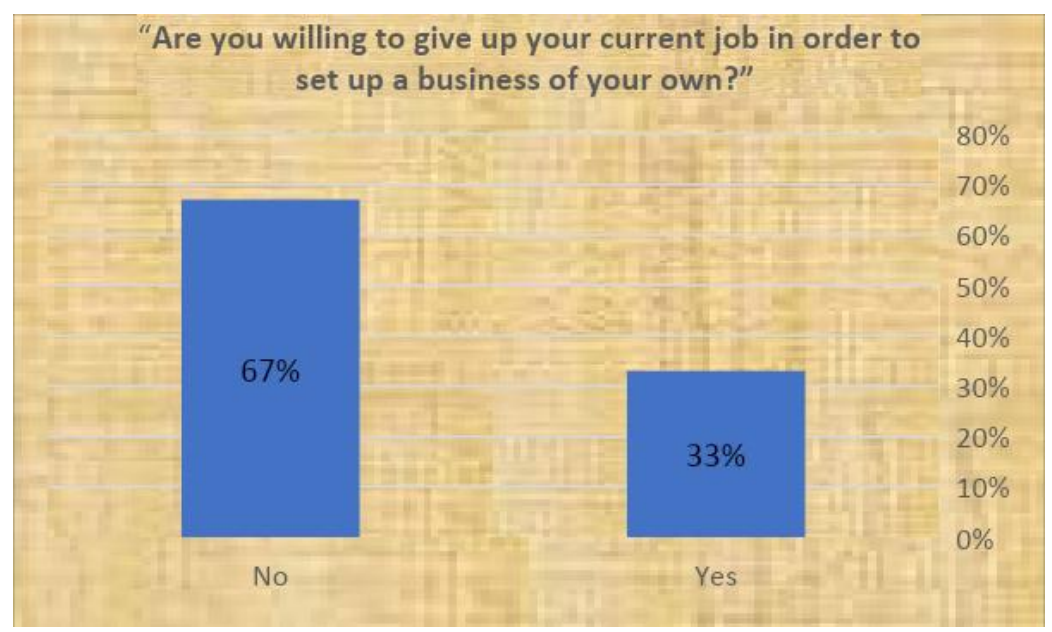

As for the question "Do you think that the level of education is essential for the success of one's business?" A majority of participants $(75 \%)$ agreed on the link between the level of education and the success of the commercial project. 


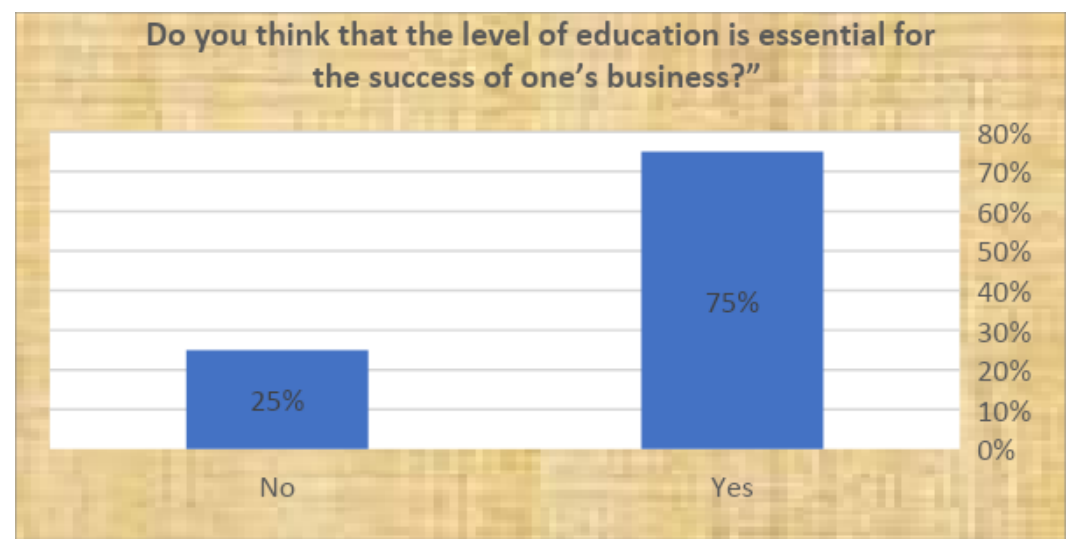

As for question 10: "Are you willing to take the risk solely while setting up your business project?" The responses were very encouraging where 64\% responded with "Yes", which indicates the courage and willingness of the Saudi youth to take risks, even solely.

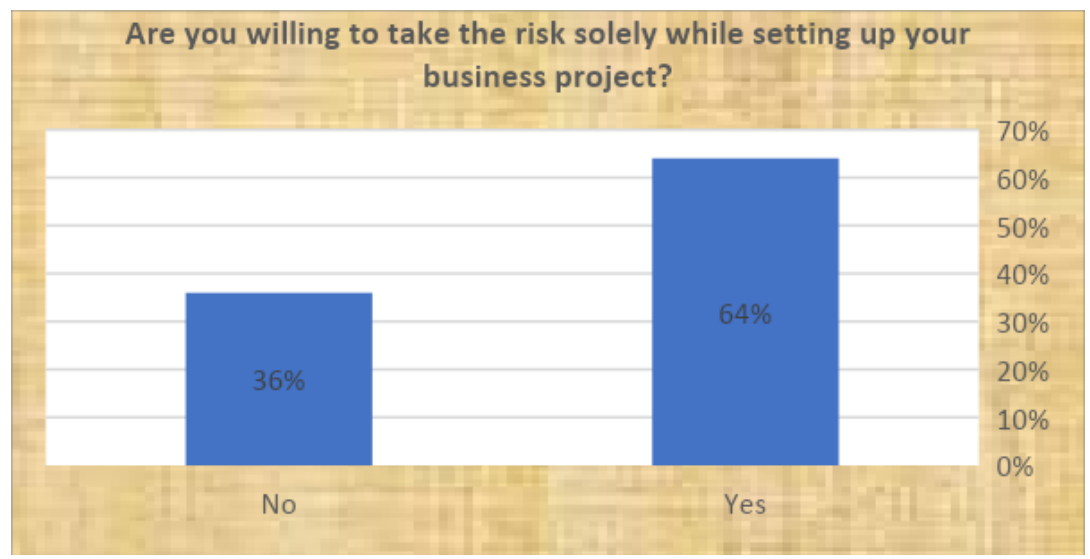

As for the eleventh question: "If your business were to fail after it started, would you repeat the attempt to build a project again?" The responses were also very encouraging where $80 \%$ of participants answered "Yes". This indicates that Saudi Arabia is a fertile and good environment to encourage small businesses and entrepreneurship.

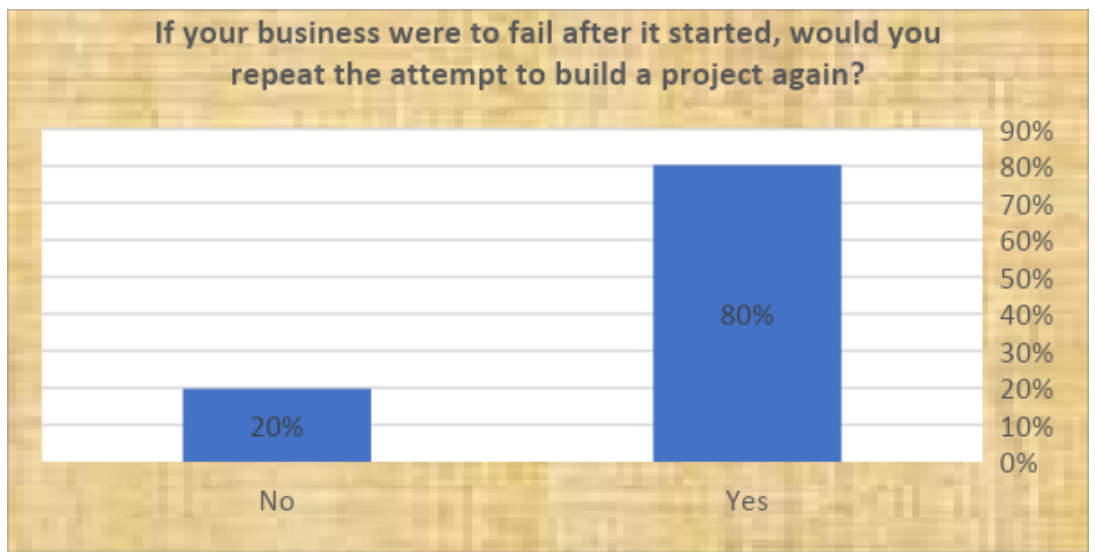

As for the 12th question: "Do you think that these projects contribute to increasing the employment opportunities of the Saudi youth and reduce dependence on government jobs?" The answers were as follows: "Strongly agree: 63\%", "Agree: $35 \%$ ", while the answer "No" was only $2 \%$. This indicates that there is a high level of awareness of the role of small businesses and entrepreneurship in reducing unemployment and increasing job opportunities. 


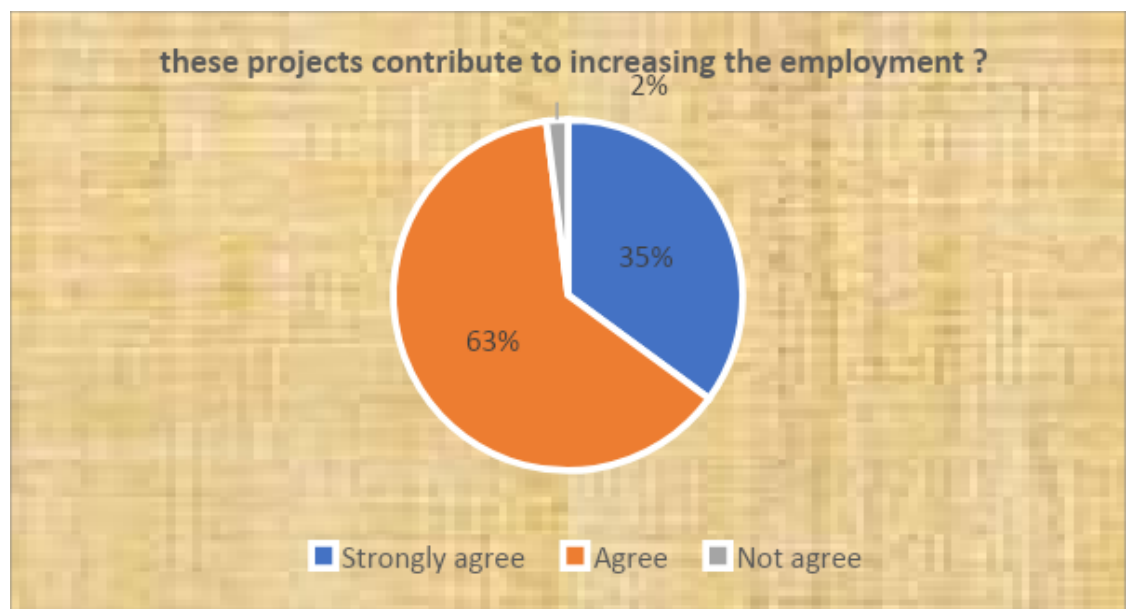

As for question 13: "Are there entrepreneurs within your family?" The answers were very close with $51 \%$ of participants answered "yes" and 49\% answered "No". This indicates an excellent sample for the study.

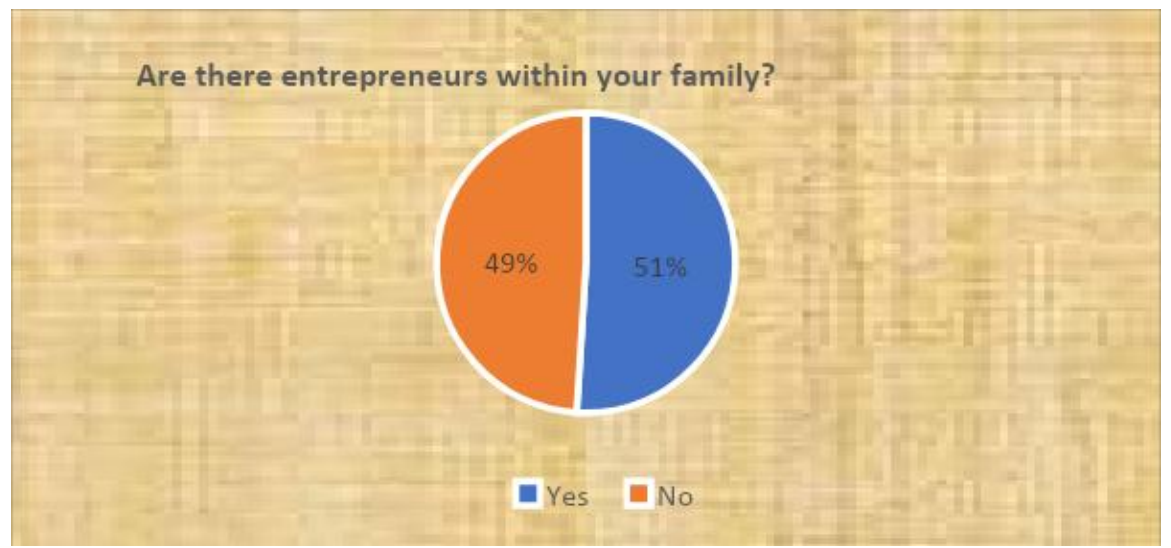

As for the question: "Are there entrepreneurs within your friends or acquaintances?" $82 \%$ of the participants answered "Yes". This means that a large percent of the sample is acquainted by entrepreneurs.

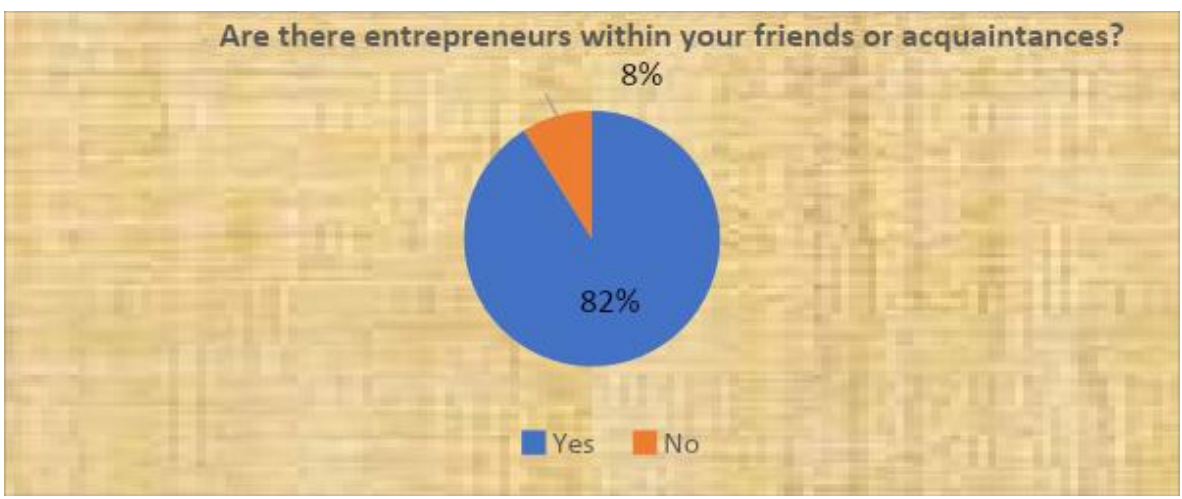

As for the question: "What is the biggest motive for you to start your own project?" The answers were divided into three main categories: having a privately owned project (30\%), using examples of successful entrepreneurs as role models $(31 \%)$ and being financially supported $(30 \%)$. The rest of the motives were represented by small percentages. 


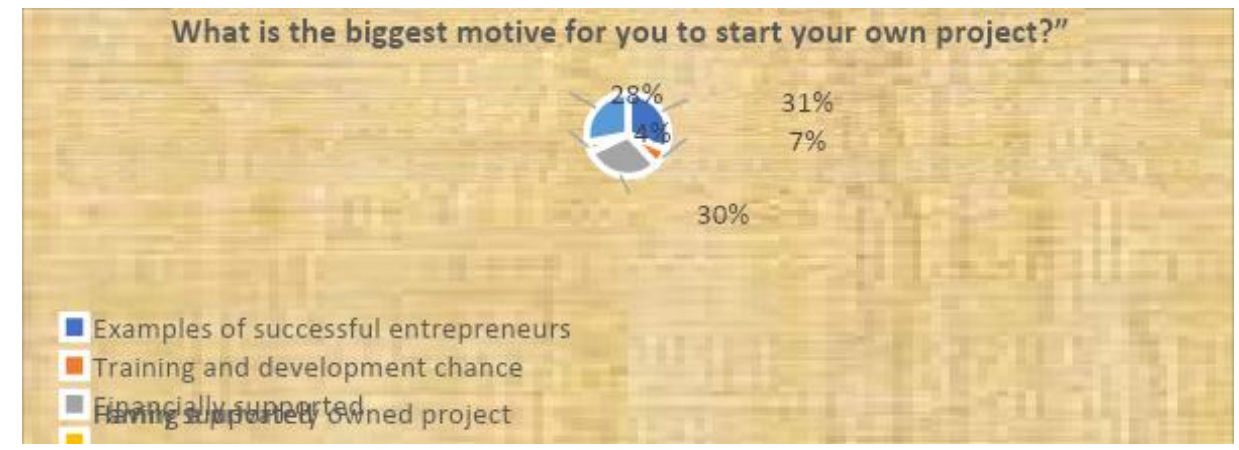

As for the sixteenth question: "What is the biggest obstacle between you and the establishment of your own project?" The answers focused on debt and financial obligations by (41\%), fear of failure (18\%) and difficulty making the decision (14\%). After that, came family obligations and the deficiency in the required skills by almost close percentages $(14 \%)$.

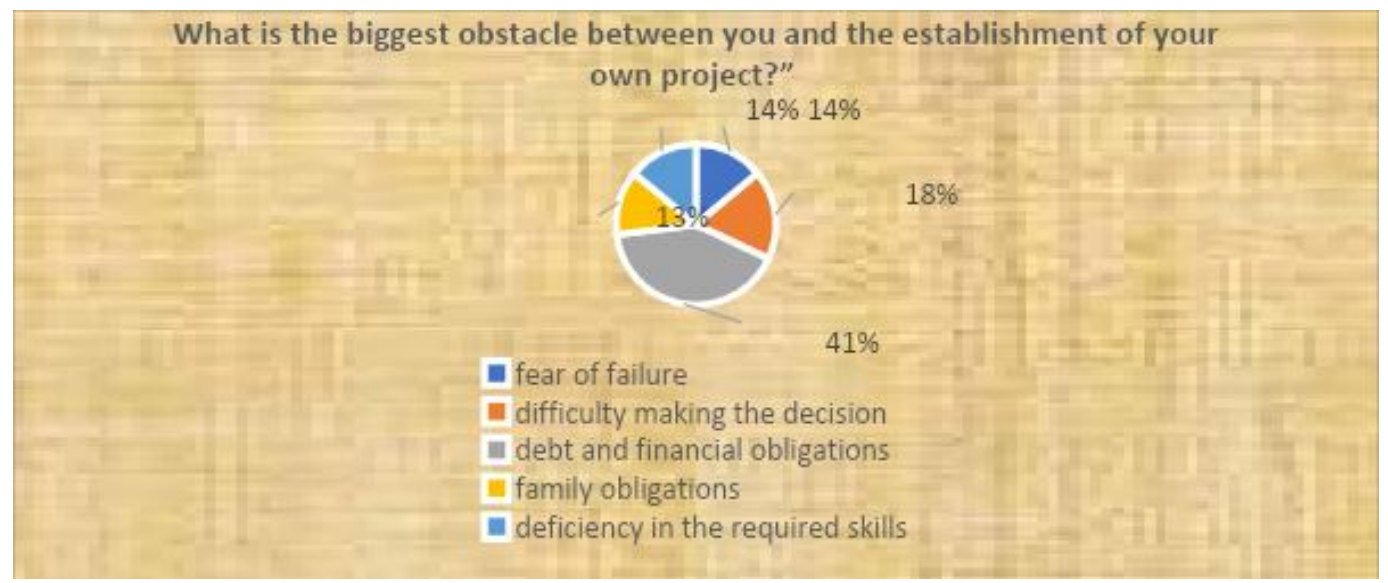

As for the seventeenth question: "In your opinion, are women in the Kingdom interested in entrepreneurship and small companies?" The answer was "Yes" by $80 \%$ even though $85 \%$ of the answers to the questionnaire came from males.

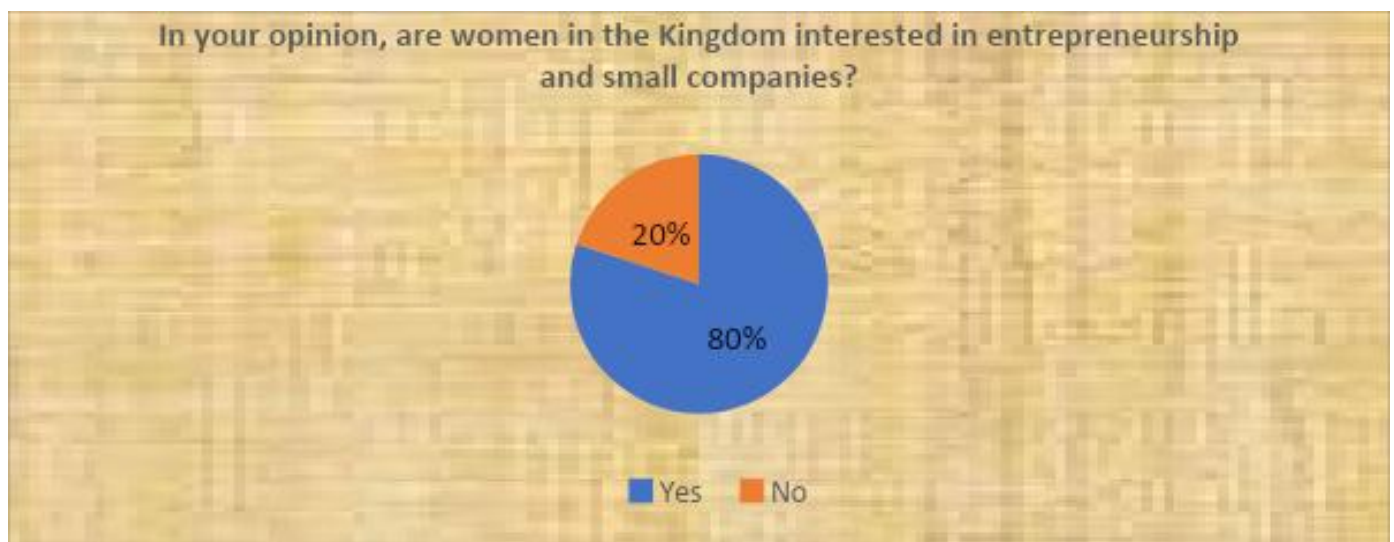

Question 18 Do you think the media has an influential role in entrepreneurship? Participants agreed that the media had an influential role in the field of entrepreneurship The answers were "yes" by $95 \%$. 


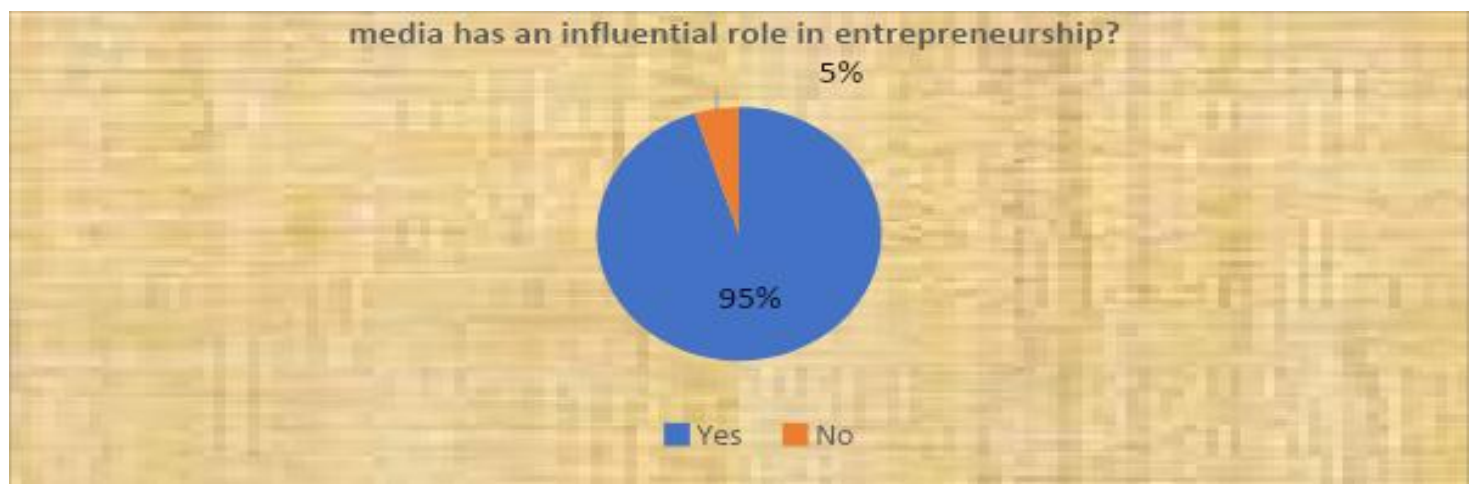

As for question 20 "whether you are interested in the existence of a magazine specialized in entrepreneurship" The answers were "yes" by $77 \%$.

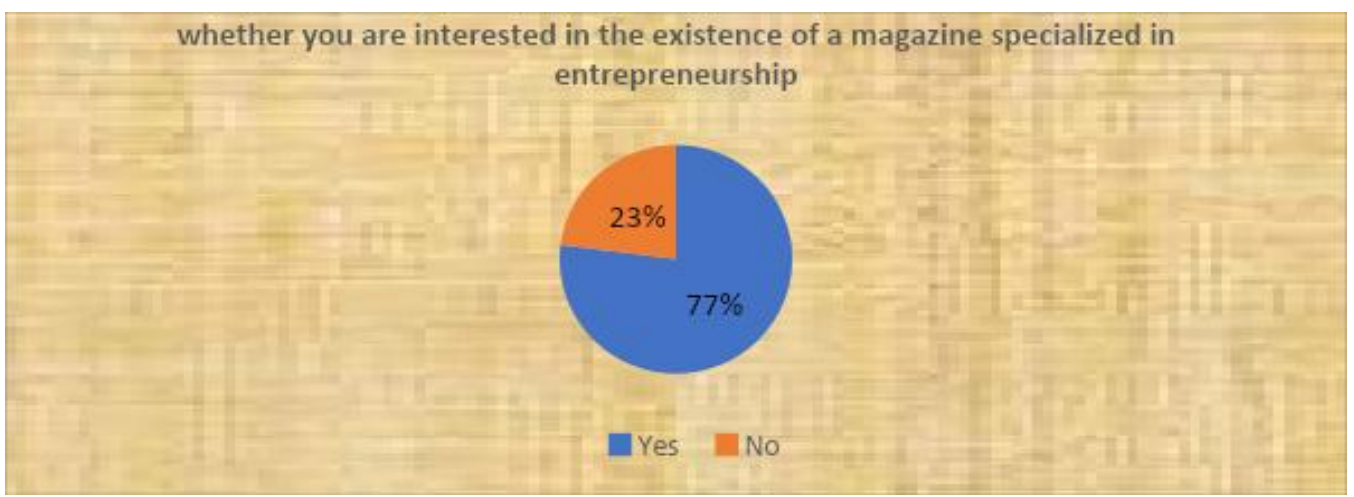

As for the last question, is it that you have seen or seen the magazine "Entrepreneurs", the answer was "yes" by $64 \%$.

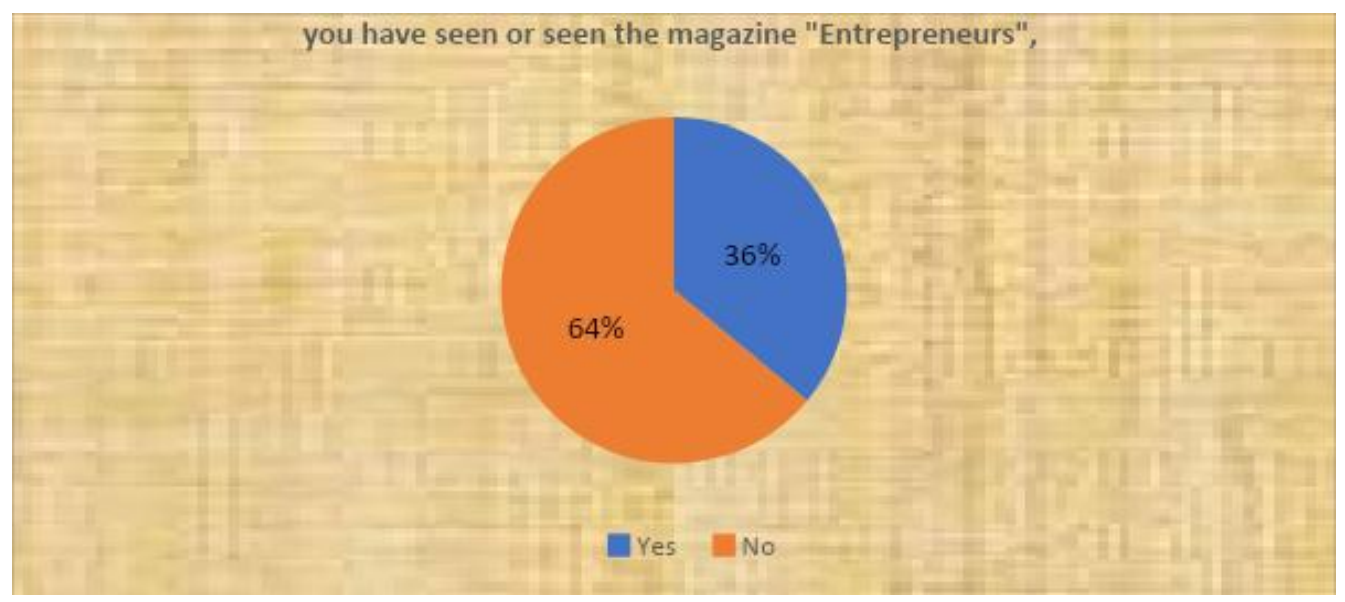

9. The Role of the Government of the Kingdom of Saudi Arabia in Encouraging Small and Medium Entrepreneurship and in Reducing Unemployment

1. The government should reduce the regulatory burden on smaller firms.

2. The government should foster secondary stock markets for small firms to allow easy entry and exit for venture investors; easing taxes on capital gains and other dividends, and allowing greater use of stock options as compensation in small firms.

3. The government should be fostering business angel networks so as to bring together small companies and prospective investors.

4. The government should reduce paperwork and bureaucracy, minimize administrative burdens, streamline procedures and reduce compliance costs for SMEs including setting up "one-stop shops: This is essential 
because high compliance costs, extensive and complicated paperwork, and economic regulations that prohibit certain activities for SMEs are major complications that these enterprises.

5. The government should be promoting enterprise clusters: The problem is that SMEs have relatively weak bargaining power and generally poor liquidity; this makes them strongly dependent on regulatory frameworks that guarantee the reliability of transactions and secure orderly playing rules in the economy which in turn causes such enterprises to be locked into their routine and unable to introduce innovative ideas. Promoting clusters will enhance SME performance and competitiveness as well as make these enterprises attain the advantages of large firms while retaining the benefits of specialization and flexibility.

6. The government (whether local, regional or national) should foster small-firm linkages through providing the frameworks for the public, private and inter-firm partnerships.

7. The government's role in building clusters is generally indirect and concerned with supporting skills development and freeing up resources while overcoming constraints to greater enterprise interaction.

8. The government should implement programs to increase the technology base of SMEs including R\&D tax credits, loans or grants for innovative activities, and technology diffusion schemes: This is essential because in most OECD countries, SME units or agencies are charged with promoting small business development by providing capital, reforming fiscal practices, reducing administrative burdens, providing management and skills training, improving information dissemination and increasing access to markets.

9. The government should also adopt an "evaluation culture" where programs are reviewed on a regular basis to determine their relevance and effectiveness as most OECD countries are now doing. Evaluation of SME programs is essential to justify their cost and to assist in the design of future programs.

10. The Saudi Authorities planners should create a supportive cultural environment for the youth towards entrepreneurship: where sufficient educational system that fosters an entrepreneurial generation should be implemented. Creativity, innovation, inventiveness skills should be taught.

11. The Saudi Authorities planners should also improve monitoring and evaluation, as well as coordination with the private sector in order to maximize the impacts of these policies.

12. The challenge of enhancing conditions for SME competitiveness goes beyond the bodies directly responsible for SME policies: the provision of an appropriate regulatory, legal and financial framework conducive to small firm start-up and growth depends on a wide range of institutions at all levels of government - local, regional, national and international.

13. In view of the SME role in economic restructuring, governments should above all promote entrepreneurship, facilitates firm start-up and expansion, and improve access to venture capital and other types of financing.

14. Local entrepreneurial support strategies should be aligned with the country's development plans under national policy for an integral entrepreneurship agenda. What is needed most is an intelligent and cultural environment, which encourages entrepreneurial behavior, focusing on knowledge, innovation and creative work that would serve high growth entrepreneurship.

15. Entrepreneurship should be encouraged to create more jobs and to reduce youth unemployment. At the same time, it should be noted that we could not depend on the high unemployment to steam more new business. It seems that unemployed youth have no strong incentive to be self-employed. High unemployment implies a lower level of personal income that is required to fund and start a business. There is also another counter-argument that unemployed tend to retain lower bequests of human capital and entrepreneurial aptitudes that are required to start a business and sustain an enterprise. Educational and Awareness policies should be recognized to foster entrepreneurial inspiration. Furthermore, an individual who is an entrepreneur by nature has strong entrepreneurial aspirations, and will not wait for a job or to be unemployed to start his own business.

16. While the Saudi government is making notable efforts to convalesce the women's participation and employment, a numeral of traditional, social, legislative and occupational aspects continue to obstruct the sufficient participation of Saudi females in the labor market.

\section{Summary \& Conclusions}

Unemployment is an important economic and social problem in the majority of GCC countries. Getting an accurate and internationally comparable evaluation of its magnitude is therefore essential. The suitable measure of 
unemployment is likely to rely on the purpose at hand. Unemployment can be used as an indicator of inflationary weights in the labor market, as a gauge of social hardship or as a measure of underutilization of labor. It is, however, not necessarily the same set or the same number of persons that are of interest in each of these cases. This research paper aims to clarify what unemployment is and the reason that causes it, as well as suggest Small and Medium Enterprises as a solution for the unemployment issue in the GCC countries in general and Saudi Arabia in particular, a problem which has a negative impact on production capacity, economic growth and the overall development over the GCC countries.

Both qualitative and quantitative approaches are used to collect data which may contribute to a better understanding of the employment issue of Saudi young men and women. Besides; we introduce entrepreneurship Survey Questionnaire; this survey has focused mainly on understanding the relationship and interaction between unemployment and entrepreneurship. In this survey, a more balanced view is taken by examining the factors which contribute to create more job opportunities and to identify the extent to which youth accept to work in Small and medium enterprises (SMEs) and what incentives and motives enable them to do so, in addition to that, this survey aims at identifying the obstacles that prevent them from achieving such goal, the interest of women in the Kingdom in entrepreneurship and small companies and the role of media in influencing the field of entrepreneurship.

Then a solution to all these problems has been presented as well as the duty of the governments of the GCC countries, especially the Government of the Kingdom of Saudi Arabia in encouraging youth to embark on entrepreneurship projects to solve the problems of unemployment in society in general and in women.

In the last Saudi Authorities planners should seek to originate a supportive cultural environment for youth towards entrepreneurship. New policies should be adapted, begin with, a enough educational system that fosters an entrepreneurial generation. Creativity, innovation, inventiveness skills ought to be involved. It is equally important to improve monitoring and evaluation, as well as coordinate with the private sector in order to maximize the impacts of these policies.

\section{References}

Bokhari, A., Alothmany, N., \& Magbool, S. (2012). Entrepreneurship and Unemployment in The Kingdom of Saudi Arabia. Working Paper Submitted to the Saudi Economy Conference: Challenges and opportunities.

Darren, L., \& Conrad, L. (2009). Entrepreneurship and Small Business Management in the Hospitality Industry. Jordan Hill, UK: Elsevier Linacre House.

Davidsson, P. (1995). SMEs and Job Creation in Sweden. Paper presented at the OECD High-level Workshop on "SMEs: Employment, Innovation and Growth", Washington, DC.

Gibson, T., \& van der Vaart, H. J. (2008). Defining SMEs: A less imperfect way of defining Small and Medium Enterprises in Developing Countries. Brookings Global Economy and Development, September 2008.

Jimmy, H., \& Pauric, M. (1999). A qualitative approach to developing small firm marketing planning competencies. Qualitative Market Research: An International Journal, 2(3), 167-175.

Johns, N., \& Mattsson, J. (2005). Destination development through entrepreneurship: a comparison of two cases. Tourism Management, 26(4), 605-616.

Lucky, E. O., \& Olusegun, A. I. (2012). Is Small and Medium Enterprises (SMEs) an Entrepreneurship?. International Journal of Academic Research in Business and Social Sciences, 2(1), 487-496.

Marcati, A., Guido, G., \& Peluso, A. M. (2008). The role of SME entrepreneurs' innovativeness and personality in the adoption of innovations. Research Policy, 37, 1579-1590.

Murphy, L., Benckendorff, P., Loscardo, G., \& Pearce, P. L. (2011). Tourist Shopping Villages: Forms and Functions. New York: Routledge, p.26.

Naudé, W. (2008). Entrepreneurship in Economic Development. Research Paper, United Nations University-WIDER, United Nations University, No. 2008/20, p.3.

Ogundele, O. J. (2007). Introduction to Entrepreneurship Development, Corporate Government and Small Business Management (1st ed.). Lagos: Molofin Nominees.

Schumpeter, J. A. (1934). The Theory of Economic Development: An Inquiry into Profits, Capital, Credit, Interest, and the Business Cycle. New York: New York University Press.

Stephen, F., \& Michael, M. (2013, November). Solving unemployment for GCC national. Performance Journal, 5(4). 